\title{
Disturbed calcium and phosphate homeostasis during treatment with ACTH of infantile spasms
}

\author{
R RIIKONEN, O SIMELL, J JÄÄSKELÄINEN, J RAPOLA, AND J PERHEENTUPA \\ Children's Hospital, University of Helsinki, Helsinki, Finland
}

SUMMARY Kidney histology of five infants who died during or immediately after treatment with adrenocorticotrophic hormone (ACTH) showed severe tubular and interstitial calcinosis. We therefore studied serum concentrations of calcium, inorganic phosphate, and parathormone, serum activities of alkaline phosphatase, and urinary excretion of calcium, inorganic phosphate, and cyclic adenosine monophosphate (cAMP) in 16 other children with infantile spasms before, during, and after 6 weeks of treatment with ACTH. During the treatment the following observations were made: (1) hypocalcaemia developed in three infants; (2) the mean daily urinary excretion of calcium in the group increased threefold and seven infants had hypercalciuria; (3) the excretion of phosphate increased but its tubular reabsorption remained stable; and (4) in most infants serum parathormone and urinary cAMP excretion increased, and in four infants they increased to supranormal concentrations. These biochemical changes were reversible in most infants. Radiographs suggested loss of bone mass by $3-4$ weeks of treatment, with rapid recovery after treatment. We conclude that infants treated with ACTH for infantile spasms are at risk of suffering disturbance in calcium and phosphate homeostasis, which leads to nephrocalcinosis.

For 25 years adrenocorticotrophic hormone (ACTH) has been the drug of choice for infantile spasms. It usually abolishes the seizures, and relapses are less common than with conventional anticonvulsive treatment. ${ }^{1}$ The dosage used varies from 10 to 180 units daily and the duration of treatment from three weeks to 10 months.

In a study of 162 infants treated with long acting ACTH at this hospital side effects, in some cases grave, were more common than in previous reports. ${ }^{2}$ In two of the infants serum calcium and inorganic phosphate concentrations and serum alkaline phosphatase activity were followed during the treatment; the concentrations and activity were low and the infants developed osteoporosis. These findings and an earlier report on ACTH induced osteoporosis in children ${ }^{3}$ prompted a (retrospective) study of the kidneys of five infants with fatal outcome of this treatment and a (prospective) study of its effects on mineral metabolism. Our findings suggest that nephrocalcinosis is common and mineral homeostasis is often disturbed, even during the relatively short six week (but high dose) treatment used at this hospital.

\section{Material and methods}

The kidneys of five infants with fatal outcome of treatment with ACTH were examined (retrospective series). We then studied (prospective series) 16 of the 22 infants treated at this hospital for infantile spasms during a two year period (Table). All infants were given carboxymethylcellulose corticotrophin (Acortan prolongatum, Ferring, Malmö, Sweden) intramuscularly every morning for six weeks. Three of the infants in the retrospective series and all the infants in the prospective series received 120 units during weeks 1 to 3 and 60 units during weeks 4 and 5. Treatment was tapered during and stopped at the end of week 6 . The two other infants in the retrospective series received one half of that dosage.

Before treatment each infant was assessed for aetiology (Table). Four infants had had no previous treatment and 12 received anticonvulsants before and during treatment with ACTH. From age 2-3 weeks every infant had been supplemented with 1000 IU vitamin D daily. The diet consisted of an adapted milk formula (the whey:casein ratio being 60:40), with supplemental food from age 3 months. 
672 Riikonen, Simell, Jääskeläinen, Rapola, and Perheentupa

Table Clinical data of 16 infants with infantile spasms treated with ACTH

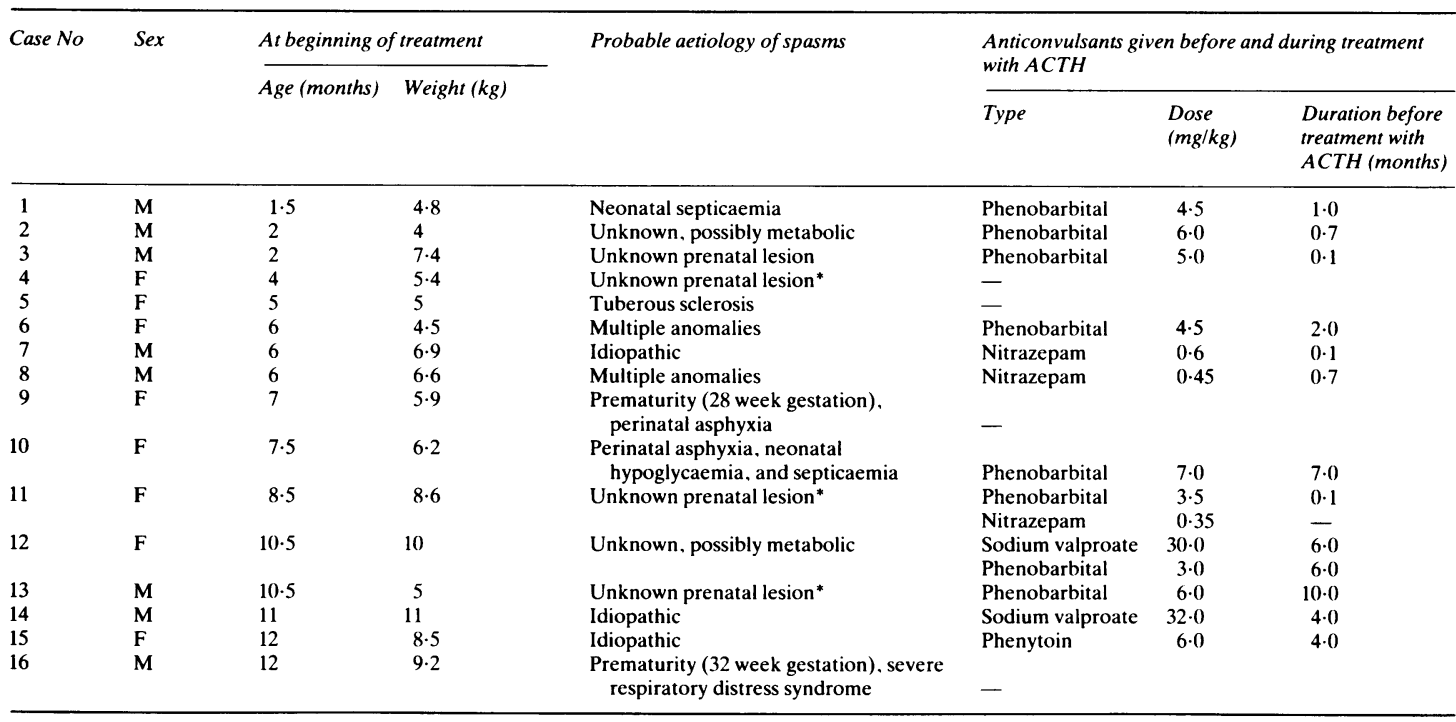

*Had signs of prenatal damage at birth (light for gestational age. or head small relative to body size).

Blood samples were taken and 24 hour urine samples collected before treatment was begun, then at three to four weeks and at the end of treatment, and two and four weeks after it. Serum and urinary calcium, phosphate, creatinine, and urea concentrations and serum alkaline phosphatase activity and magnesium, chloride, protein, and albumin concentrations were measured in all infants. The isoenzymes of alkaline phosphatase activity were also measured in eight of the infants. Urinary cyclic adenosine monophosphate (cAMP) was measured by a protein binding assay. ${ }^{4}$ Radioimmunoassayable parathormone (PTH) was determined $^{5}$ in 12 infants, using rabbit antiserum against intact bovine PTH (Medicinisk Laboratorium, Copenhagen) and Medical Research Council Standard 71/324. Amino acids in plasma and 24 hour urine of all the infants were screened by thin layer chromatography ${ }^{6}$ and, if abnormal, quantified with an automatic amino acid analyser (Beckman $121 \mathrm{M})$ using lithium buffers and norleucine as internal standard. Renal tubular reabsorption of calcium (TRCa) was calculated as $\mathrm{TRCa}=1$-calcium clearance/creatinine clearance. Tubular reabsorption of phosphate (TRP) was calculated similarly. Our reference range is $0.94-0.99$ for TRCa and 0.96-1.0 for TRP.

Radiographs from the left hand and knee of 14 infants were taken at two to four weeks during and four weeks after treatment. A paediatric radiologist
(JJ) estimated the loss of mineral in the cancellous bone by visual comparison of serial radiographs.

For statistical analysis of intraindividual changes we used Student's $t$ test for paired values. The values are given as means (SEM).

The ethics committee of the hospital approved the study. Informed consent was obtained from all parents.

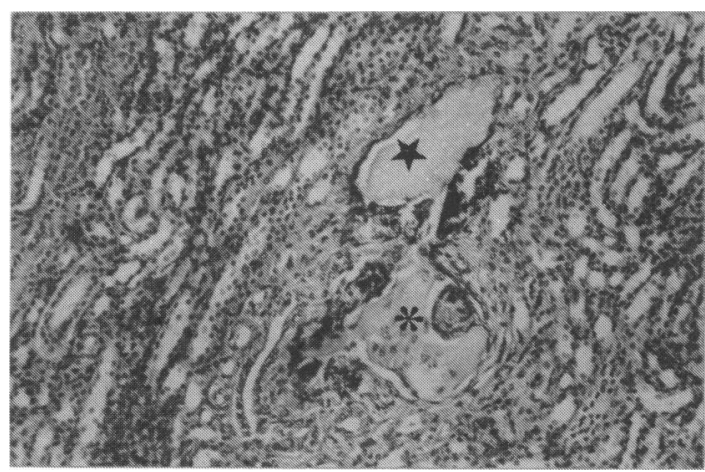

Fig. 1 The renal medulla of an infant who died of pneumonia one month after treatment with ACTH, showing intratubular and interstitial calcium deposits (star) with multinucleated giant cell reaction (asterisk) (Haematoxylin eosin staining). 
Disturbed calcium and phosphate homeostasis during treatment with ACTH of infantile spasms
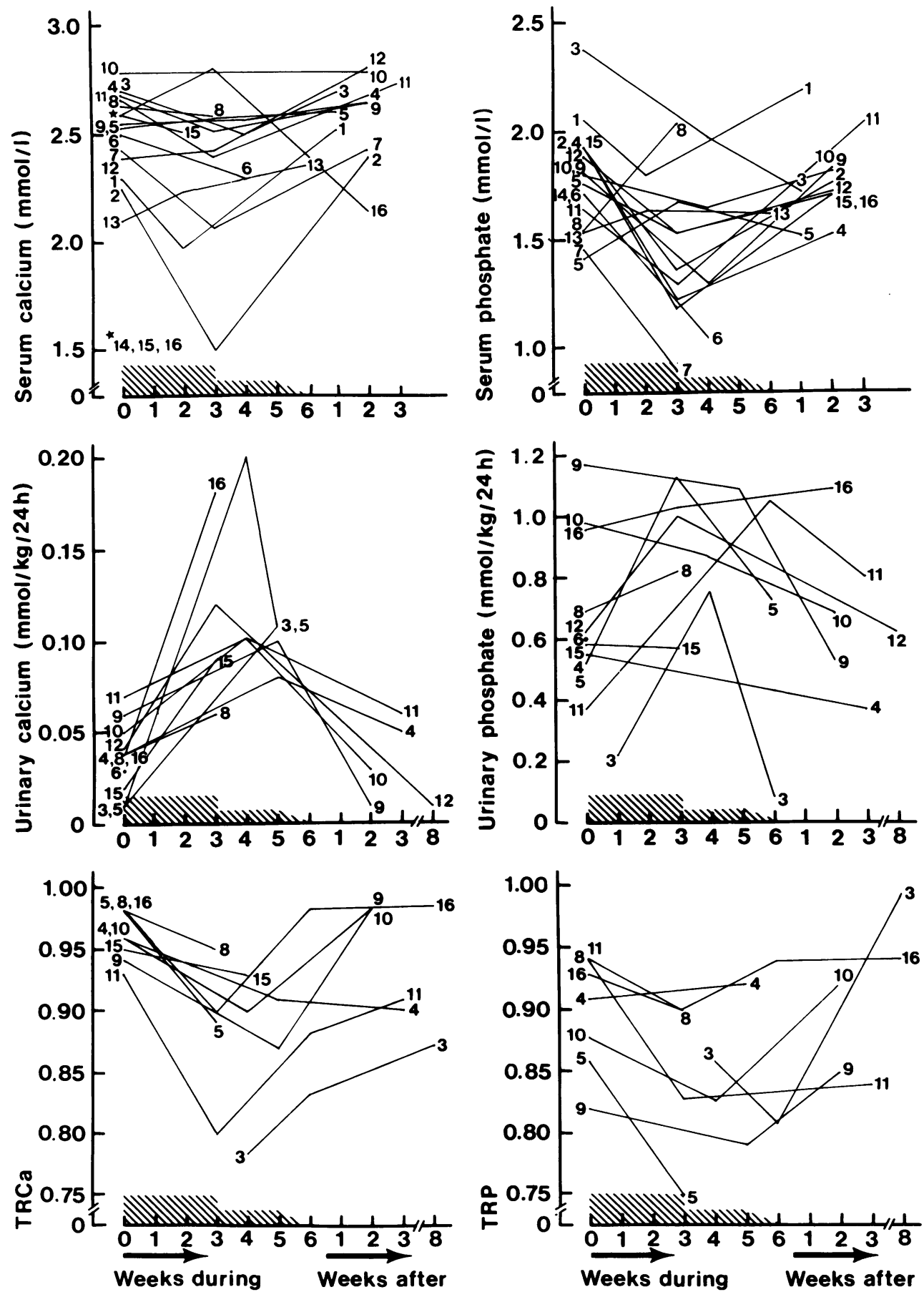

Treatment with ACTH

Treatment with ACTH

Fig. 2 Serum and daily urinary calcium and phosphate and renal tubular reabsorption of calcium (TRCa) and phosphate $(T R P)$ in infants before, during, and after six weeks of treatment with ACTH.

Conversion: SI to traditional units-Calcium: $1 \mathrm{mmol} / \mathrm{l}=4 \cdot 0 \mathrm{mg} / 100 \mathrm{ml}, 1 \mathrm{mmol}=40 \mathrm{mg}$; Phosphate: $1 \mathrm{mmol} / \mathrm{l}=3 \cdot 3 \mathrm{mg} / 100 \mathrm{ml}, 1 \mathrm{mmol}=32 \mathrm{mg}$. 


\section{Results}

Nephrocalcinosis. None of the five infants with fatal outcome (retrospective series) had signs of renal failure; they died of fulminant infections. Their kidneys were macroscopically normal. Microscopy showed severe tubular and interstitial nephrocalcinosis (Fig. 1). Three of them had had metabolic alkalosis (base excess ranging from 8 to 12). One of them had severe and two others moderate hypokalaemia $(2 \cdot 2,3 \cdot 2$, and $3 \cdot 2 \mathrm{mmol} / \mathrm{l}$, respectively); all others were normokalaemic. Urine $\mathrm{pH}$ was not measured.

All eight infants studied for urine $\mathrm{pH}$ in the prospective group had values $>7.5$ during the treatment. Three of them had metabolic alkalosis with base excess ranging from 11.5 to 11.7 $\mathrm{mmol} / \mathrm{l}$.

Serum calcium and phosphate concentrations. The mean serum calcium concentration did not change significantly during the treatment with ACTH, being $(2.53(0.05) \mathrm{mmol} / \mathrm{l}$ before and $2.39(0.09)$ $\mathrm{mmol} / \mathrm{l}$ during treatment), despite a decrease in most of the infants (Fig. 2). In three infants the concentration became subnormal and in three others supranormal.

The mean serum phosphate concentration fell from $1.79(0.06) \mathrm{mmol} / \mathrm{l}$ to $1.47(0.08)(\mathrm{p}<0.005)$ during the treatment (Fig. 1). Seven infants became hypophosphataemic. In one infant the concentration clearly increased, with a corresponding decrease in serum PTH concentration (case 8 , see below).

Daily urine calcium, phosphate, cAMP, and creatinine concentrations and amino acids. During the treatment the mean (SEM) daily urine calcium concentration increased from $0.046(0.008) \mathrm{mmol} /$ $\mathrm{kg}$ to $0.108(0.014) \mathrm{mmol} / \mathrm{kg}(\mathrm{p}<0.001)$ (Fig. 2). Hypercalciuria $(>0.1 \mathrm{mmol} / \mathrm{kg} / 24 \mathrm{~h})$ occurred in seven of 11 infants. The TRCa fell from $0.96(0 \cdot 01)$ to $0.89(0.02) \quad(p<0.001)$. Daily urine phosphate concentration increased from $0.68(0.08) \mathrm{mmol} / \mathrm{kg}$ to $0.88(0.08) \mathrm{mmol} / \mathrm{kg}(\mathrm{p}<0 \cdot 2)$. The TRP decreased from $0.90(0.02)$ to $0.84(0.02)(\mathrm{p}<0.025)$. Daily urine cAMP concentration increased from 0.04 $(0.01)$ to $0.08(0.01) \mu \mathrm{mol} / \mathrm{kg}$ during treatment $(\mathrm{p}=0.03)$.

Ten of the 16 infants developed generalised aminoaciduria; in three of them this was severe. One of the three infants (case 9) had hyperparathyroidism; serum PTH concentration was not determined in the others.

Serum alkaline phosphatase activity. Serum alkaline phosphatase activity decreased in 15 infants from
710 (637-791) IU/1 to 265 (226-312) IU/l (geometric mean (SEM); normal $<1000$ IU/l) $(\mathrm{p}<0.001)$ (Fig. 3). It increased markedly in one infant (case 9) with severe secondary hyperparathyroidism (see below). Isoenzymes were studied in eight patients (including case 9). The changes were in the thermolabile (bone) isoenzyme, which accounted for 70 to $100 \%$ of the total activity.

Serum PTH concentration. PTH concentrations increased in eight of the nine infants followed (Fig. $4)$. The geometric mean (SEM) concentration was $0.27(0.23-0.30) \mu \mathrm{g} / \mathrm{l}$ before and $0.53(0 \cdot 40-0 \cdot 70) \mu \mathrm{g} / \mathrm{l}$ during treatment. Four infants (cases $3,4,6$, and 9) had supranormal concentrations during treatment.

Other serum measurements. Serum protein, albu-

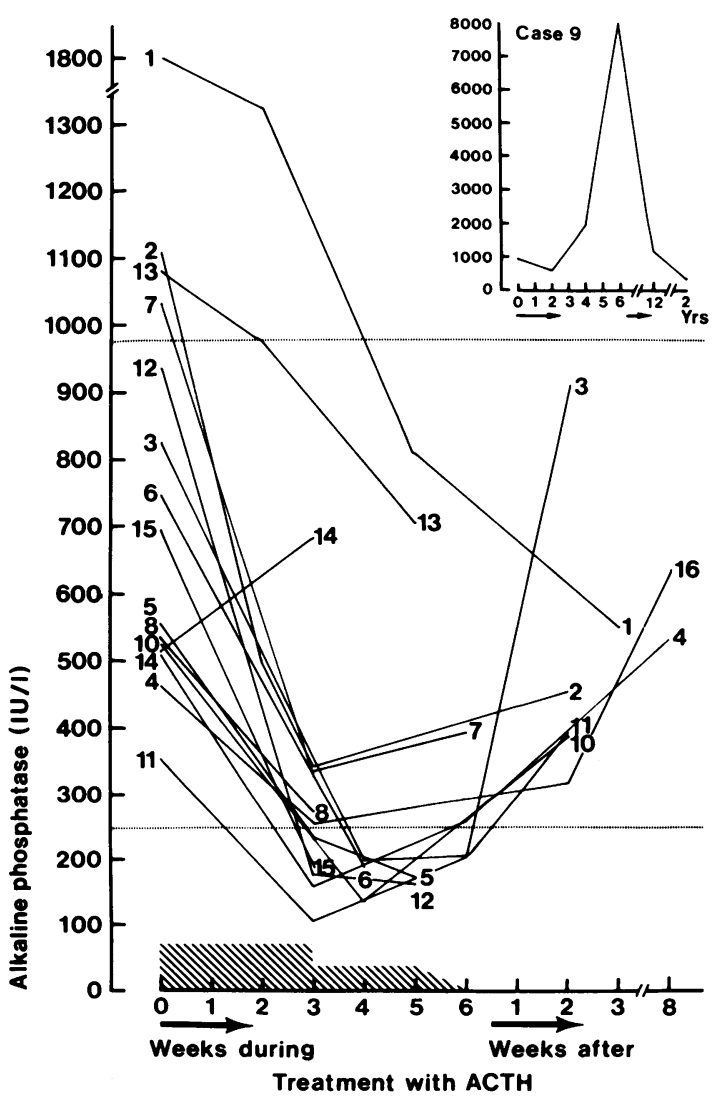

Fig. 3. Serum alkaline phosphatase activity in infants before, during, and after six weeks of treatment with $A C T H$. The area within the dotted lines represents the range of the reference values. 


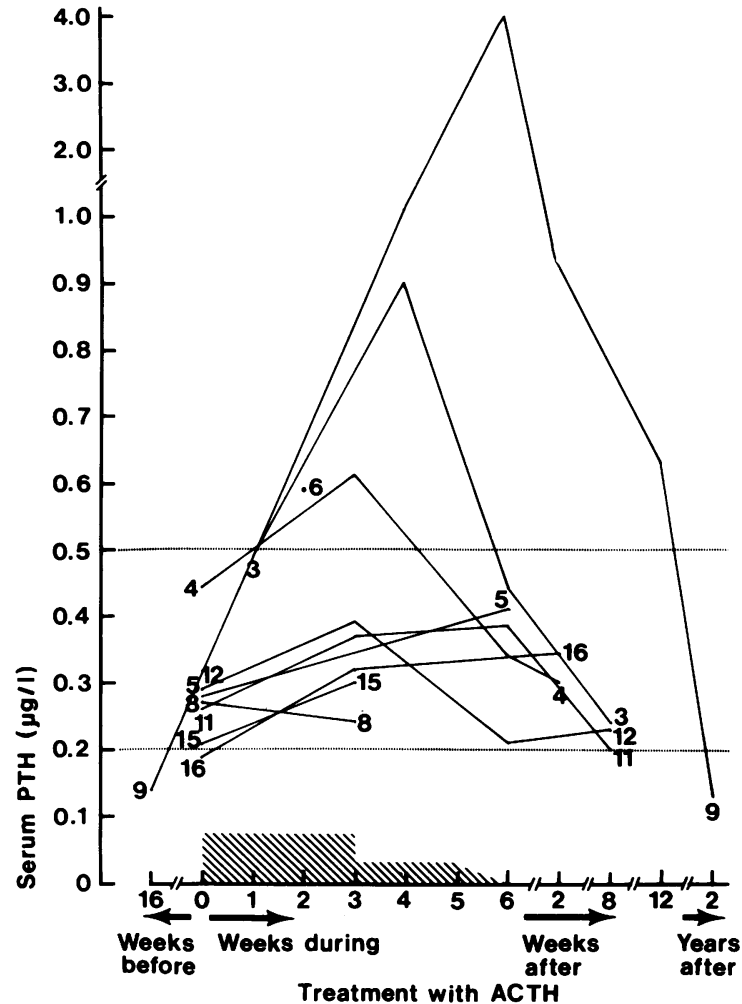

Fig. 4 Serum parathormone (PTH) concentrations in infants before, during, and after six weeks of treatment with $A C T H$. The area within the dotted lines represents the range of the reference values.

min, magnesium, creatinine, and urea concentrations were within normal limits.

Reversibility of the biochemical changes. The mean serum calcium concentration increased to 2.62 $(0.04) \mathrm{mmol} / \mathrm{l}$ after the treatment (for the difference between the values during and after treatment with ACTH $\mathrm{p}<0.01$; Fig. 2). Serum phosphate concentration increased to $1.76(0.06) \mathrm{mmol} / \mathrm{l}(\mathrm{p}<0.02)$. Daily urinary calcium and phosphate excretion decreased to pretreatment amounts, $0.37(0.01)$ $\mathrm{mmol} / \mathrm{kg} \quad(\mathrm{p}<0.02)$ and $0.68 \quad(0.10) \quad \mathrm{mmol} / \mathrm{kg}$ $(\mathrm{p}<0 \cdot 1)$, respectively. TRCa rose to $0.94(0.02)$ $(\mathrm{p}<0 \cdot 1)$ and TRP to $0.91 \quad(0.00)(\mathrm{p}<0 \cdot 1)$. The supranormal serum alkaline phosphatase activity of case 9 normalised (Fig. 3). In another seven infants followed after treatment the concentration rose to $514(450-587)$ IU/l (geometric mean (SEM)) $(\mathrm{p}<0 \cdot 2)$.

Serum PTH concentration was measured in four infants after treatment. The concentrations decreased slightly. The hyperaminoaciduria disappeared after treatment. Daily urinary cAMP also returned to lower amounts $(\mathrm{p}<0 \cdot 1)$.

Radiographic findings. Bone mass decreased in all 14 patients who had serial radiographs. The whole cancellous bone was affected. In the metaphyseal region the demineralisation occurred after only two weeks of treatment. The provisional zone of ossification contrasted sharply against the physis, giving a band like appearance.

Slight metaphyseal cupping suggested rickets in four infants (cases 2, 4, 9, and 13). Three of them had subperiosteal resorption and rarefaction of cancellous bone. Two of them were on treatment with anticonvulsants.

The radiographic changes were reversible. All eight infants restudied after treatment showed clear remineralisation of the cancellous bone.

\section{Discussion}

Treatment with ACTH induces hypersecretion of cortisol and, to a lesser extent, of adrenal androgens. Hypercortisolism may impair the intestinal absorption of calcium and phosphate, increase their renal clearance rates, induce secondary hyperparathyroidism, and cause osteoporosis. ${ }^{78}$ Some of these changes are probably mediated by cortisol induced alteration in the metabolism of vitamin $\mathrm{D} .{ }^{9}$ The hypersecretion of androgenic steroids and the metabolic alkalosis ${ }^{10}$ that result from treatment with ACTH may partially counterbalance the skeletal changes due to hypercortisolism. The net effect of treatment with ACTH on bone has been considered insignificant, but only a few studies have concerned infants. ${ }^{23}$ The harmful sequence of effects of hypercorticotropism on mineral and bone metabolism was clearly though variably evident in our series of infants.

The most alarming of these effects is the renal calcification. It has already been reported by others. ${ }^{11}$ It is not surprising that hyperparathyroidism, hypercalcaemia, hyperphosphaturia, and alkalosis should produce this complication. Oliguria, which may be present in these infants, ${ }^{2}$ provides an additional risk factor.

Most of the infants in this study received or had received treatment with anticonvulsants. With the limited number of infants treated with ACTH alone, we are unable to separate the effects of ACTH from those caused by other treatments. The results in the four children receiving only ACTH were well within the range of the results in the others.

For infantile spasms no good alternative to 


\section{Riikonen, Simell, Jääskeläinen, Rapola, and Perheentupa}

treatment with ACTH is known. Variable dosages are in use; in Scandinavia high doses have been used because they have been considered to give better results. Because of the complications it now clearly appears to be imperative that the dose and duration of this treatment is individualised and kept to the minimum required to be effective. These infants need monitoring for many variables, and especially for renal calcification (by serial echography) and hypocalcaemia. It remains to be seen whether measures other than reducing the dose of ACTH and shortening the treatment could be used to curtail these complications.

The skilful technical help of Ms Marjatta Viikari is acknowledged. This study was supported by grants from the Research Department, Rinnekoti Foundation, Finland, and the Foundation for Pediatric Research, Finland.

\section{References}

1 Lacy JR, Penry JK. Infantile spasms. New York: Raven Press, 1976:79-105.

${ }^{2}$ Riikonen R, Donner M. ACTH therapy in infantile spasms: side effects. Arch Dis Child 1980;55:664-72.

${ }^{3}$ Cret L, David M, Macebéo V, et al. Maladie des spasmes en flexion: troubles cliniques et métaboliques observés en cours de traitment par le tétracosactide zinc. Pediatrie 1976;31:33-48.
${ }^{4}$ Linkola J, Fyhrquist F. Urinary cyclic AMP and vasopressin excretion in rat strains selected for their alcohol intake. Acta Physiol Scand 1978;102:364-9.

5 Arnaud CD, Tsao HS, Littledike T. Radioimmunoassay of human parathyroid hormone in serum. J Clin Invest 1971;50: 21-9.

${ }^{6}$ Simell O, Sipilä I, Autio S. Extra heating of TLC plates detects two lysosomal storage disease, aspartylglucosaminuria and fucosidosis, in routine urinary amino acid screenings. Clin Chim Acta 1983;133:227-32.

${ }^{7}$ Harrison HE, Harrison HC. Disorders of calcium and phosphate metabolism in children. Philadelphia: W B Saunders, 1979:27.

${ }^{8}$ Aurbach GD, Stephen JM, Allen MS. Parathyroid hormone, calcitonin and calciferols. In: Williams RH, ed. Textbook of endocrinology, 6th ed. Philadelphia: W B Saunders, 1981: 961-1011.

${ }^{9}$ Chesney RW, Mazess RB, Hamstra AJ, DeLuca HF O'Reagan S. Reduction of serum-1,25-dihydroxyvitamin-D3 in children receiving glucocorticoids. Lancet 1978;ii:1123-5.

${ }^{10}$ Myles AB, Daly JR. Corticosteroid and ACTH treatment: principles and problems. London: Edward Arnold, 1974:98-105.

" Rausch H, Hanefeld F, Kaufmann H. Medullary nephrocalcinosis and pancreatic calcifications demonstrated by ultrasound and CT in infants after treatment with ACTH. Radiology 1984:153:105-7.

Correspondence to Dr R Riikonen, Children's Hospital, University of Helsinki, SF-00290 Helsinki, Finland.

Received 3 February 1986 